\title{
Clinico-epidemiological profile of childhood cutaneous tuberculosis
}

\author{
Shrestha $S B^{l}$, Pokhrel $G P^{2}$, Pradhan $S B^{3}$ \\ ${ }^{1,2}$ Department of Dermatology \& S.T.I. and ${ }^{3}$ Pathology \\ Kathmandu Medical College \& Teaching Hospital, Kathmandu, Nepal.
}

\begin{abstract}
Introduction: Although cutaneous tuberculosis constitutes a small percentage of extra pulmonary tuberculosis, it has not been fully documented in Nepal and more so in the pediatric population.

Objectives: The aim of the study was to assess the epidemiology and clinical profile of childhood cutaneous tuberculosis at Kathmandu Medical College and Teaching Hospital, Nepal.
\end{abstract}

Material and Methods: Children (below 15 years of age) with cutanesous tuberculosis who attended the teaching hospital between April 2008 and March 2014 were studied.

Results: A total of 17 children with skin tuberculosis were identified during the study period, which constituted $34 \%$ of all patients with skin tuberculosis. There were 11 boys and 6 girls with a mean age of 8.8 years. The duration of the lesions ranged from 1 month to 4 years and $13(76.5 \%)$ were brought for medical help after six months of onset of the disease. Lower limb was the most common site of involvement. Of the various patterns of cutaneous tuberculosis; scrofuloderma was the most common 7 (41.2\%) followed by lupus vulgaris $6(35.3 \%)$, erythema nodosum $2(11.7 \%)$ and gumma $1(5.8 \%)$. Combination of lupus vulgaris and scrofuloderma was noted in one patient. Three patients $(17.6 \%)$ had internal organ involvement as pulmonary tuberculosis.

Conclusion: The pattern of skin tuberculosis had wide variation with a few of them having systemic involvement. Therefore, these patients need a thorough evaluation or an uniform standard therapeutic regimen to cover both internal organ and cutaneous tuberculosis.

Keywords: Clinical profile, Skin tuberculosis, Nepalese children

\author{
Address for correspondence \\ Dr. Sanju Babu Shrestha \\ Department of Dermatology and S.T.I. \\ Kathmandu Medical College \& Teaching Hospital \\ 184 Baburam Acharya Marg \\ Sinamangal, Kathmandu, Nepal. \\ P.O.Box 21266 \\ Fax No.: 977-1-4477920 \\ E-mail: sanrekha2000@yahoo.com
}




\section{Original Article}

\section{Introduction}

Tuberculosis continues to be a major public health problem worldwide, because of adverse social conditions, development of multi-drug resistant strains of Mycobacterium tuberculosis, ineffective public health surveillance programmes and the emergence of HIV infection. ${ }^{1}$ Extrapulmonary tuberculosis constitutes around $10 \%$ of all cases of tuberculosis and cutaneous tuberculosis represents only $1.5 \%$ of all cases of extrapulmonary tuberculosis. ${ }^{2}$ Cutaneous tuberculosis has a varied clinical presentation, determined by the pathogenicity, route of infection as well as status of cellular immunity of the host. ${ }^{3}$ In children, drug compliance is usually poor and the immune system is not well developed which are compounded in the above mentioned problems.

The paucity of studies from this part of the world prompted us to undertake the study with the aim to assess the epidemiology and clinical profile of childhood cutaneous tuberculosis in a tertiary care hospital of Kathmandu, Nepal.

\section{Material and Methods}

This is a descriptive study where all newly diagnosed patients of cutaneous tuberculosis $(<15$ years age) who attended the department of Dermatology and STI in Kathmandu Medical College and Teaching Hospital (KMCTH), Kathmandu between April 2008 and March 2014 were included. Statistical analysis was conducted by means of SPSS statistical software for Windows (version 10.0, SPSS Inc, Chicago, IL, USA). Descriptive statistics were reported through number and percentage for categorical responses and mean and standard deviation for continuous variable. A detailed history was taken with particular reference to $B C G$ vaccination and tuberculosis in the family. Clinical features including the cutaneous and systemic examination were recorded in a preset proforma. BCG vaccination was confirmed by the presence of a small circular scar in the left deltoid region. The skin biopsy from the advancing edge of the lesion or the edge of the sinus tract lesion was performed and was divided into two portions, one part processed for histopathological evaluation after staining with hematoxylin and eosin and the other portion used for culture of mycobacteria in Lowenstein-Jensen medium. The Mantoux test was performed by intradermal injection of 0.1 $\mathrm{ml}$ of purified tuberculin on the volar surface of the forearm; induration was measured after 72 hours in all patients. Induration of more than $10 \mathrm{~mm}$ was taken as suggestive of infection with M. tuberculosis. Fine needle aspiration of the lymph nodes was undertaken whenever indicated.To rule out tuberculosis in other organs, chest X-ray and sputum-smear examination for acid-fast bacilli (AFB) on 3-consecutive days were done for all patients. Patients were classified according to the morphology of the lesions described in standard texts. Whenever any systemic organ was involved or if there was a presence of generalized lymphadenopathy, the disease was classified as disseminated. Haemogram, liver, and renal function tests were done before starting therapy. Later the patients were given three or four anti-tubercular drugs regimen for 6-8 months as per Nepal national tuberculosis treatment guideline.

\section{Results}

A total of 17 children with skin tuberculosis were identified during the study period, which constituted $34 \%$ ( 17 out of 50 ) of all patients with skin tuberculosis. There were 11 boys and 6 girls with a mean age of 8.8 years (1.5-14 \pm 3.57 years). The duration of the lesions ranged from 1 month to 4 years and $13(76.5 \%)$ were brought for medical help after six months of onset of the disease. Lower limb was the most common site of involvement seen in $47 \%$ cases, followed by neck, face, and trunk. Fifteen children were BCG vaccinated however it was doubtful in 2 patients because neither a definite scar nor a record of receiving a $B C G$ vaccination was available. Only one child had family history of pulmonary tuberculosis. The mantoux test was positive in $12(70.5 \%)$ patients. Histopathology revealed tuberculoid granuloma in eight children, caseation necrosis was found in four cases. In two cases, histopathology showed erythema nodosum and one case showed nonspecific features in the form 


\section{Original Article}

of chronic inflammatory infiltrate. Table 1 profiles of these patients. summarizes the main clinico-epidemiological

Table 1: Clinical and epidemiological profile of children with cutaneous tuberculosis

\begin{tabular}{|c|c|c|c|c|c|c|c|c|c|c|c|}
\hline 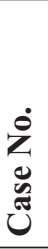 & 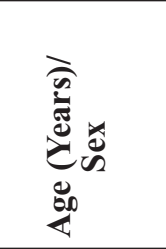 & 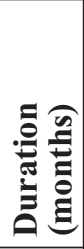 & 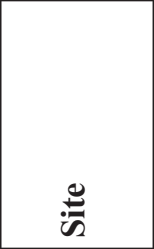 & 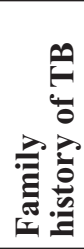 & 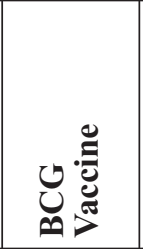 & 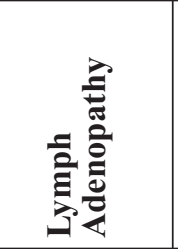 & 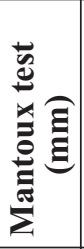 & 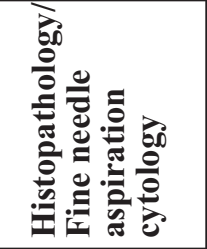 & $\frac{\mathscr{c}}{\sqrt[0]{2}}$ & 密苞 & 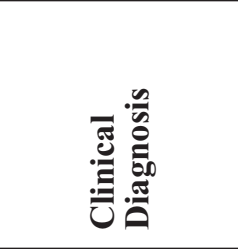 \\
\hline 1 & 7/Male & 24 & Rt axilla & Yes & Yes & $\begin{array}{l}\text { Axillary, } \\
\text { Inguinal } \\
\text { cervical }\end{array}$ & 20 & $\begin{array}{l}\text { Caseation } \\
\text { necrosis } \\
+ \text { epitheloid } \\
\text { granuloma }\end{array}$ & 22 & NAD & Scrofuloderma \\
\hline 2 & 5/Male & 24 & Rt. ankle & No & Yes & $\mathrm{NO}$ & $>30$ & $\begin{array}{l}\text { Tuberculoid } \\
\text { granuloma }\end{array}$ & 28 & NAD & Lupus vulgaris \\
\hline 3 & 10/Male & 3 & Neck & No & Doubtful & $\begin{array}{l}\text { Cervical, } \\
\text { axillary }\end{array}$ & $>20$ & $\begin{array}{l}\text { Epitheloid } \\
\text { granuloma }\end{array}$ & 35 & NAD & Scrofuloderma \\
\hline 4 & 7/ Male & 18 & Rt. Axilla & No & Yes & Rt. Axillary & 20 & $\begin{array}{l}\text { Epitheloid } \\
\text { granuloma }\end{array}$ & 30 & NAD & Scrofuloderma \\
\hline 5 & 10/Male & 48 & Rt. Ankle & No & Yes & Axillary & 15 & $\begin{array}{l}\text { Caseation } \\
\text { necrosis } \\
+ \text { epitheloid } \\
\text { granuloma }\end{array}$ & 40 & NAD & $\begin{array}{l}\text { Scrofuloderma } \\
\text { Lupus vulgaris }\end{array}$ \\
\hline 6 & 9/ Male & 12 & Buttock & No & Doubtful & NO & $<5$ & $\begin{array}{l}\text { Tuberculoid } \\
\text { granuloma }\end{array}$ & 20 & NAD & Lupus vulgaris \\
\hline 7 & 10/ Female & 24 & Rt thigh & No & Yes & NO & 5 & $\begin{array}{l}\text { Tuberculoid } \\
\text { granuloma }\end{array}$ & 55 & NAD & Lupus vulgaris \\
\hline 8 & 14/ Female & 5 & Face & No & Yes & Cervical & 17 & \begin{tabular}{l|} 
Chronic \\
inflammatory \\
infiltrate
\end{tabular} & 38 & NAD & Scrofuloderma \\
\hline 9 & 11/ Female & 36 & Face & No & Yes & $\mathrm{NO}$ & 10 & $\begin{array}{l}\text { Tuberculoid } \\
\text { granuloma }\end{array}$ & 20 & NAD & Lupus vulgaris \\
\hline 10 & 14/ Female & 5 & Lt. leg & No & Yes & $\mathrm{NO}$ & 22 & $\begin{array}{l}\text { Erythema } \\
\text { nodosum }\end{array}$ & 45 & NAD & $\begin{array}{l}\text { Erythema } \\
\text { nodosum } \\
\text { Scrofuloderma }\end{array}$ \\
\hline 11 & 5/ Male & 6 & Back & No & Yes & $\begin{array}{l}\text { Axillary } \\
\text { (both) }\end{array}$ & 15 & $\begin{array}{l}\text { Caseation } \\
\text { necrosis } \\
+ \text { epitheloid } \\
\text { granuloma }\end{array}$ & 30 & NAD & $\begin{array}{l}\text { Lupus vulgaris }+ \\
\text { Pulmoanary- }\end{array}$ \\
\hline 12 & 6/ Male & 8 & Rt. Knee & No & Yes & $\mathrm{NO}$ & $<5$ & $\begin{array}{l}\text { Tuberculoid } \\
\text { granuloma }\end{array}$ & 29 & Opacity & tuberculosis \\
\hline 13 & 12/ Female & 6 & Neck & No & Yes & Cervical & 20 & $\begin{array}{l}\text { Epitheloid } \\
\text { granuloma }\end{array}$ & 52 & Fibrosis & Scrofuloderma \\
\hline 14 & 12/ Male & 18 & Rt. Leg & No & Yes & $\begin{array}{l}\text { Inguinal } \\
\text { (both) }\end{array}$ & 5 & $\begin{array}{l}\text { Tuberculoid } \\
\text { granuloma }\end{array}$ & 32 & NAD & Lupus vulgaris \\
\hline 15 & 1.5/ Male & 1 & Neck & No & Yes & $\begin{array}{l}\text { Cervical } \\
\text { Axillary }\end{array}$ & $>10$ & $\begin{array}{l}\text { Epitheloid } \\
\text { granuloma }\end{array}$ & 80 & $\begin{array}{l}\text { Hilar } \\
\text { lympha } \\
\text { denitis }\end{array}$ & Scrofuloderma \\
\hline 16 & 5/ Female & 1 & Rt. Leg & No & Yes & $\mathrm{NO}$ & 20 & $\begin{array}{l}\text { Erythema } \\
\text { nodosum }\end{array}$ & & NAD & $\begin{array}{l}\text { Erythema } \\
\text { nodosum }\end{array}$ \\
\hline 17 & 12/ Male & 6 & Chest & No & Yes & NO & 30 & $\begin{array}{l}\text { Ill-define } \\
\text { granuloma }\end{array}$ & & NAD & Gumma \\
\hline
\end{tabular}


Vol. 13, No. 1, 2015

\section{Original Article}

Table 2: Age, sex distribution of the cases

\begin{tabular}{|c|c|c|c|c|c|c|c|c|c|}
\hline \multirow[b]{2}{*}{ Age (in years) } & \multicolumn{2}{|c|}{$\begin{array}{c}\text { Lupus Vulgaris } \\
\text { (LV) }\end{array}$} & \multicolumn{2}{|c|}{$\begin{array}{l}\text { Scrofuloderma } \\
\text { (SFD) }\end{array}$} & \multicolumn{2}{|c|}{$\begin{array}{l}\text { Erythema } \\
\text { Nodosum }\end{array}$} & \multicolumn{2}{|c|}{ Gumma } & \multirow[t]{2}{*}{ Total } \\
\hline & M & $\mathrm{F}$ & M & $\mathrm{F}$ & M & $\mathrm{F}$ & $\mathrm{M}$ & $\mathrm{F}$ & \\
\hline $0-4$ & - & - & 2 & - & - & _ & - & _- & $2(11.76 \%)$ \\
\hline $5-9$ & 3 & - & 2 & - & - & 1 & - & - & $6(35.29 \%)$ \\
\hline $10-14$ & 1 & 2 & 2 & 2 & - & 1 & 1 & - & $9(52.94 \%)$ \\
\hline Total (\%) & \multicolumn{2}{|c|}{$6(35.29 \%)$} & \multicolumn{2}{|c|}{$8(47.06 \%)$} & \multicolumn{2}{|c|}{$2(11.76 \%)$} & \multicolumn{2}{|c|}{$1(5.88 \%)$} & $17(100 \%)$ \\
\hline
\end{tabular}

M- Male, F-Female

Of the various patterns of cutaneous tuberculosis seen, $8(47.06 \%)$ had scrofuloderma, $6(35.3 \%)$ had lupus vulgaris, $2(11.7 \%)$ had erythema nodosum, and 1child had a gummatous ulcer on the chest. Combination of lupus vulgaris and scrofuloderma was noted in one patient. Figure 1-3 depicted the various pattern of cutaneous tuberculosis. Three patients had internal organ involvement as pulmonary tuberculosis. All patients were treated with three or four antitubercular drug regimen for 8 months as per Nepal national tuberculosis treatment guideline.

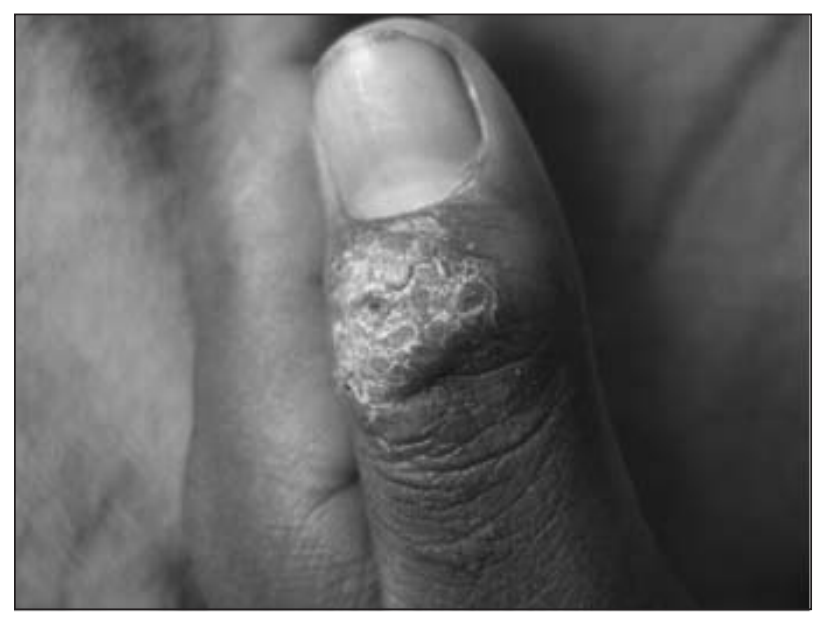

Figure 2: Lupus vulgaris over right index finger and right foot

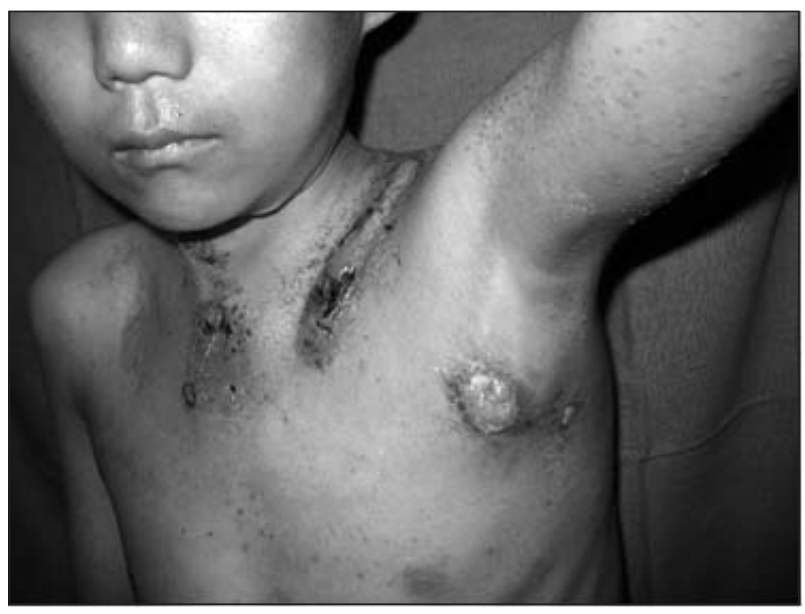

Figure 3: Scrofuloderma in the neck and axilla region 


\section{Original Article}

\section{Discussion}

The incidence of childhood cutaneous tuberculosis varied worldwide from $12.8 \%$ to $31.7 \%$ in India ${ }^{3}$, ${ }^{4}$ and $36.3 \%$ in Hong Kong. ${ }^{5}$ In the present series, $34 \%$ of the total numbers of patients with skin tuberculosis were children. In contrast to the previous studies ${ }^{4,6}$, boys outnumbered girls in our study.

Thirteen $(76.5 \%)$ children brought for medical help after six months of onset of the disease in our study. Delay in diagnosis may occur because of scarce attentions paid by parents during the early stages of the disease and when they seek advice it is often from practitioners who are little exposed to this uncommon condition. Therefore, sometimes misdiagnosis, ${ }^{7}$ neglect, or late diagnosis ${ }^{8}$ in children may result in extensive disease. The definitive diagnosis of skin tuberculosis employ smear and culture examination for demonstration of acid fast bacilli but are tedious and unrewarding. ${ }^{4,9,10}$ Mantoux test positivity was noted in $70.5 \%$ in our series. This was probably because, in children with localized disease, sensitization occurred due to the presence of the disease, or was induced by $\mathrm{BCG}$, exposure to related environmental mycobacteria, or M. tuberculosis from infected close contacts. Mantoux negativity was probably due to the extent of the disease, malnutrition, and other related factors. ${ }^{6}$ In our study, although a good clinico-histopathological correlation was observed and was supported by a positive Mantoux test, yet smear examination with ZiehlNeelsen as well as culture on Lowenstein-Jensen media were unsuccessful.

In the last couple of decades newer techniques have emerged for the rapid detection, isolation and identification of mycobacteria. These include fluorescent microscopy11, DNA probe identification, ${ }^{11}$ high performance liquid chromatography, ${ }^{12}$ polymerase chain reaction, ${ }^{13}$ serological diagnosis14 and DNA finger printing. ${ }^{15}$ Newer methods are gradually being incorporated into the testing schedules which will revolutionize the early and /or definitive diagnosis of tuberculosis in future. However, these tests, apart from being expensive, need well equipped laboratories and are not available in our hospital.

It is difficult to define the role of BCG. Some have found no significant difference between vaccinated and unvaccinated groups, ${ }^{2}$ others have hinted at a modification in the severity, ${ }^{16}$ and a recent report indicated moderate protection against skin tuberculosis. ${ }^{17}$ Eighty eight percent of the children in this study had BCG vaccinations. Two had doubtful BCG vaccination however both of them had localized disease; scrofuloderma and LV. Occasionally LV occurring at the site of BCG vaccination has been seen, ${ }^{10}$ suggesting exogenous inoculation of the infection similarly in one of our patient had lupus vulgaris on the buttock following intramuscular injection.

Lower limb was the most common site of involvement in our study. The reason stated for the predominance in the lower parts of the body is the lack of clothing in a large number of children who acquire the infection while playing. ${ }^{9}$

Cutaneous manifestations of tuberculosis are polymorphous in both children and adults. Scrofuloderma (SFD) was the commonest type of cutaneous tuberculosis in our series similar to the other studies ${ }^{6,18}$ reported from India. This is probably due to consumption of unboiled/ unpasteurized milk which is a common phenomenon in India and which may subsequently lead to infection of cervical lymph-nodes by $M$. bovis via the tonsils with development of SFD. In India, in general, SFD is more frequent in children, unlike in Europe where adults are more often affected with this type of presentation. ${ }^{19}$ This may be due to differences in the source of infection, endogenous reactivation being more common in Europeans. ${ }^{19}$ Lupus vulgaris (LV) the second most common forms in our study, demonstrating a finding probably related to the improvement in health conditions and general availability of vaccination programs countrywide and increases the immunity against $M$. tuberculosis. The keratotic form of Lupus vulgaris was the most common followed by the hypertrophic and ulcerative varieties. 


\section{Original Article}

Mycobacterial infection in LV can be acquired through both exogenous and endogenous routes, and may assume warty forms. ${ }^{2,18}$

Wong et al from Hong Kong reported TVC in as high as $65.5 \%$ of their children and SFD in only $16.3 \%$ of their children, ${ }^{5}$ however in contrast, $41.2 \%$ of children in our series had SFD and none had TVC. Similarly Kumar et al reported SFD in $51.2 \%$ and TVC in only $4.4 \% .^{2}$

Regional lymphadenopathy is seen more often in children with disseminated disease and thus appeared to be a soft indicator of disease dissemination. In the present study the cervical lymph nodes were most commonly affected in SFD. A larger number of children were seen in the younger age groups, as in another hospitalbased study. ${ }^{20}$ In one report, SFD was the most common form seen in children, especially girls. ${ }^{21}$ Children are not only prone to develop SFD but the lesions, even when localized appear severe when compared to those of adults. ${ }^{22}$ More than one form of skin tuberculosis can affect a patient. ${ }^{10}$, ${ }^{23}$ This presentation seems to be comparatively uncommon in children, as single child with LV and SFD was seen in this study. Scrofuloderma of the chest wall was associated with pulmonary tuberculosis. Erythema nodosum was noted in $11.7 \%$ in our study in contrast to $1.3 \%$ tuberculides reported by Kumar et al from India. Tuberculous gumma was present in only 1 patient, compared to the incidence reported in the literature. Primary skin tuberculosis and acute miliary skin tuberculosis were also not seen in this series. The former may present as a chancre due to exogenous infection in children exposed to tubercle bacilli for the first time or as noduloulcerative lesions secondary to BCG inoculation in infants. ${ }^{24}$ Acute miliary skin tuberculosis is seen rarely in children following exanthems ${ }^{25}$ or in disorders that predispose to poor immune status. ${ }^{26}$

One child had evidence of active foci of tuberculous infection in the lungs. The incidence of tubercular lymphadenitis in children with LV was much greater when compared to that in adults. ${ }^{10}$ We have noted lupus vulgaris with scrofuloderma in one patient. Three patients had internal organ involvement as pulmonary tuberculosis. In the spectrum of cutaneous tuberculosis there are a proportion of patients with dissemination (systemic involvement) who are of great epidemiological significance as they require a change in the standard therapeutic regimens recommended for cutaneous tuberculosis.

In conclusion, scrofuloderma and lupus vulgaris were the most frequent form of cutaneous tuberculosis and are important causes of morbidity. There is a high likelihood of internal involvement, especially in patients with scrofuloderma. Therefore, all cutaneous tuberculosis patients need a thorough evaluation for internal organ involvement and need a uniform standard therapeutic regimen to cover both internal and cutaneous tuberculosis.

\section{References}

1. Marcovel J, Servitje O, Moreno A, Jucgla A, Peyri J. lupus vulgaris: Clinical, histopathological and bacteriologic study of 10 cases. J Am Acad Dermatol 1992; 26: 404-7. http://dx.doi.org/10.1016/0190-9622(92)70062-K

2. Kumar B, Kaur S. Pattern of cutaneous tuberculosis in north India. Indian J Dermatol Venereol Leprol 1986; 52: 203-7.

3. Sehgal VN, Jain MK, Srivastava G. Changing pattern of cutaneous tuberculosis: A prospective study. Int J Dermatol 1989; 28: 231-6. http://dx.doi.org/10.1111/j.1365-4362.1989.tb04810.x

4. Ramesh V, Samuel B, Misra RS, Nath I. In situ characterization of cellular infiltrates in lupus vulgaris indicates lesional $\mathrm{T}$ cell activation. Arch Dermatol 1990; 126: 3315.http://dx.doi.org/10.1001/archderm.1990.01670270063010

5. Wong KO, Lee PK, Chiu SF. Tuberculosis of the skin in Hong Kong: a review of 100 cases. Br J Dermatol 1968; 80: 424-8. http://dx.doi.org/10.1111/j.1365-2133.1968.tb11977.x 


\section{Original Article}

6. Kumar B, Rai R, Kaur I, Sahoo B, Muralidhar S, Radotra BD. Childhood cutaneous tuberculosis: a study over 25 years from northern India. Int J Dermatol 2001; 40: 26-32. http://dx.doi.org/10.1046/j.1365-4362.2001.01165.x

7. Prendiville J, Kaufman D, Esterly NB. Psoriasiform plaque on the buttock. Arch Dermatol 1989; 126: 113-8. http://dx.doi.org/10.1001/archderm.1989.01670130119021

8. Mohamed KN. Verrucous lesions in children in the tropics. Ann Trop Paediatr 1990; 10: 273-7.

9. Mitchell PC. Tuberculosis among Chinese in Hong Kong. Br J Dermatol 1954; 66: 444-8. http://dx.doi.org/10.1111/j.1365-2133.1954.tb12576.x

10. Pandhi RK, Bedi TR, Kanwar AJ, Bhutani LK. Cutaneous tuberculosis-a clinical and investigative study. Indian J Dermatol 1977; 22: 99-107.

11. Tenover FC, Crawford JT, Huebner RE, Geiter LJ, Horsburgh CR Jr, Good RC. The resurgence of tuberculosis: Is your laboratory ready? J Clin Microbiol 1993; 31: 767

12. Butler WR, Jost KC. Kilburn JO. Identification of mycobacteria by high performance liquid chromatography. J Clin Microbiol 1991; 31: 2468.

13. Clarridge JE, Shawar R.M, Shinnick TM, . Large scale use of polymerase chain reaction for detection of mycobacterium tuberculosis in a routine mycobacteriology laboratory. $\mathrm{J}$ Clin Microbiol 1993; 31: 2049.

14. Daniel TM, Debanne SM. The serodiagnosis of tuberculosis and other mycobacterial diseases by enzyme-linked immunosorbent assay. Am Rev Respir Dis 1987: 135: 1137-51.

15. Cave MD, Eisenach KD, McDermott PF, Bates JH, Crawford JT. conservation of sequence in Mycobacterium tuberculosis comples and its utilisation in DNA fingerprinting. Mol Cell Probes 1991; 5: 73. http://dx.doi.org/10.1016/0890-8508(91)90040-Q

16. Sehgal VN, Bhattacharya SN, Jain S, Logani K. Cutaneous tuberculosis: The evolving scenario. Int J Dermatol 1994; 33: 97-104. http://dx.doi.org/10.1111/j.1365-4362.1994.tb01534.x

17. Zodpey SP, Shrikhande SN, Maldhure BR, Kulkarni SW. Effectiveness of bacillus Calmette Guerin (BCG) vaccination in the prevention of tuberculosis of skin: a case control study. Indian J Dermatol 1998; 43: 4-6.

18. Singh G. Lupus vulgaris in India. Ind J Dermatol 1974; 40: 257-60.

19. Yates VM, Ormerod LP. Cutaneous tuberculosis in Blackburn district (U.K.): a 15 year prospective series. Br J Dermatol 1997; 136: 483-9. http://dx.doi.org/10.1111/j.1365-2133.1997.tb02127.x

20. Visser AJ, Heyl T. Skin tuberculosis as seen at Ga-Raukuwa hospital. Clin Exp Dermatol 1993; 18: 507-15. http://dx.doi.org/10.1111/j.1365-2230.1993.tb01019.x

21. Som DD, Swan DD, Tie TE, Pho OB. Tuberculosis cutis in children. Paediatr Indones 1965; 5: 527-34.

22. Anand IS, Gupta S. Profile of skin disorders in children in Saurashtra. J Indian Med Assoc 1998; 96: 245-6.

23. Satyanarayana BV. "Tuberculoderma"- a brief review together with statistical analysis and observations. Indian J Dermatol Venereol Leprol 1963; 29: 25-42.

24. Gangopadhyay AK. Scrofuloderma-an unusual complication of BCG vaccination. Indian J Dermatol 1997; 42 :249-50.

25. Kakakhel KU, Fritsch P. Cutaneous tuberculosis. Int J Dermatol 1989; 28: 355-62. http://dx.doi.org/10.1111/j.1365-4362.1989.tb02478.x

26. Frix CD, Bronson DM. Acute miliary tuberculosis in a child with anhidrotic ectodermal dysplasia. Pediatr Dermatol 1986; 3: 464-7. http://dx.doi.org/10.1111/j.1525-1470.1986.tb00652.x 